\title{
Educational research between on devices and mobile learning
}

\author{
Lucia Martiniello $^{\mathrm{a}}$, Nicola Paparella ${ }^{\mathrm{b}}$ \\ ${ }^{a}$ Lucia Martiniello, Università telematica Pegaso,Italy, lucia.martiniello@unipegaso.it,0000-0002-5194- \\ 6061 \\ ${ }^{b}$ Nicola Paparella, Università telematica Pegaso, Italy,nicola.paparella@unipegaso.it, 0000-0003-3095- \\ 1184
}

\begin{abstract}
The great potential of mobile learning devices hooks up these new contexts that are, above all, cultural and social, but also organisational and relational, forcing us to reconsider fundamental themes of pedagogical discourse. Among these themes, the first must be the construction of the student's identity and, connected to this, the issue of personalised education. Let us consider, for instance, the by-now familiar distinction between formal, informal and non-formal. Compared with formal learning, we have always considered the two conditions of informal and non-formal education as independent or at least parallel, but essentially distinct and fundamentally different. In the moment in which teaching is done through mobility, and therefore with the effects of interference in contexts completely different from those that are somewhat predictable by the designer of distance learning, can we still think of a "distinction" between formal and informal or, at least, should we not assume a sort of context cross-breeding?

The question does not arise from considerations of quantitative, but instead arises from qualitative, evaluations.

In our opinion, here exists a paradigm: the learning context not only escapes the teaching team's realm of predictability, but somehow eludes even the predictability of the learner, and indeed, it is the very nature of the context that takes completely different characteristics and connotations.

We are on the verge of justifying a major revision of some paradigms that relate to the nature of the context, the role of the teacher and the position (in the sociological sense) of the student, which also affect the nature of the message and, more generally, the "entire educational setting". It means working in this direction.
\end{abstract}

Keywords: educational research, mobile devices, mobile learning, context, educational setting

If the impact of personal computers, in the context of educational issues, shook up some of the parameters and changed the borders of traditional and online teaching, mobile Internet devices (MIDs) seem to put some underlying paradigms in crisis.

The widespread diffusion of mobile phones, smartphones, tablets, personal digital assistants (PDAs), laptops, Moving Picture Experts Group Layer-3 Audio (MP3) players, and global positioning system (GPS) receivers has caught us all a little off guard because, speaking solely from a technological point of view, the reduced processing and storage capabilities, due to the smaller hardware sizes compared with the standards of fixed devices, could dash the hopes for a prosperous market.

What did not pass unnoticed, however, is the specificity of these instruments and, therefore, their own unique potential due to their being "mobile", and the market has generously met these expectations, due to - it should be noted-some definite progress in efficiency.

A few years ago an American study made a lot of news, which proved that in 2013 (Frank Weishaupt, 2013), half of the time surfing on the Internet was done through mobility tools, with a particularly interesting peak in the numbers for women aged between 25 and 49 years; in some cases (14\%), access to the Internet was only through the mobile phone, especially tablets and smartphones. If we add the statistics for young males (18-24 years old) to this demographic group (women aged 25-49 years), we get the group of Internet users whose majority of browsing time is spent on mobiles.

Today, we know that the growth rate of "Internet use with mobile devices" has not been interrupted; on the contrary, it has obtained further confirmation. In Italy, for instance, in the second half of June 2016, with the second edition of the investigation Media Consumption Forecasts, the Zenith Optimedia of Milan let know that the growth in the number of people who will devote part of their time in Internet use from mobile devices will increase to $27.7 \%$ in 2016 , leading to a growth of $1.4 \%$ of the overall use of the media. 


\section{Educational research between on devices and mobile learning Martiniello, Paparella}

It follows that on the basis of what happens for the Internet mobile, all the other devices are in decline. In 2016, it is estimated that at year end, cinema may observe a contraction - in terms of time of consumption - of $0.5 \%$, billboards of $0.8 \%$, television of $1.5 \%$, radio of $2.4 \%$, dailies of $5.6 \%$ and magazines of $6.7 \%$. It could be useful to keep in mind that in the analysis of media consumption patterns and in the trend assessment of the time that people devote to media consumption, Zenith takes into account data from 71 countries all over the world, six more than the 65 countries considered in 2015.

The analysis considered follows business reasons in that it tries to understand how an advertising message should be displayed on Web pages; they allow few reasons of insights to those who design educational/training courses. And if as Frank Weishaupt, chief operating officer of Jumptap ${ }^{1}$, said: “Gone are the days when company's reached the consumer with a message on only one device," then educational directors can now take note of how elusive context learning has become, especially distance learning.

Despite there being some initial hesitation, those involved in learning now take for granted the idea that we are in the midst of a change that cannot be dismissed as a simple tribute to fashion or the development of technical and economic interests that are now working together (Hayes et al., 2005).

On the other hand, in this cultural (and social) period that is dominated by extensive use of mobile devices, one expects that these tools would be put to use to accomplish learning processes, both in the most obvious contexts, such as ordinary school, as well as in far more complex contexts, such as in vocational training and distance education, especially adult learning.

As has always been the case, the impact of technology on education has inevitably led us to review both the morphology of teaching and its parameters, and these, in turn, lead us to re-examine the manner of that impact, or to otherwise renegotiate items and factors, according to a spiral that somehow goes on to envisage stages of crisis (evolutionary), which in turn calls for adjustments, which then derive additional moments of crisis and further stages of development.

When one intercepts the many requests coming from the universe of mobility communication tools, one can gather, along with some sure operational strengths, some critical elements that together represent a total of at least four separate problems, one of them being interconnected with the other three. We will just make a few notes on the first three, because they will be revisited in other investigations in which the authors of the current study are working on and also because they only serve to introduce the fourth critical point, which appears to be the root of the problem, i.e. the possible paradigmatic importance of the issue.

We hypothesise that the impact of mobility tools, along with the initiatives of distance learning, urges or causes a deconstruction (and a consequent reconstruction) of core teaching paradigmatic nodes.

a) The first question, under an appearance of simplicity and perhaps even obviousness, contains resonances and entanglements that push beyond the reflection of the teaching methods, and instead enter into grounds of philosophy, anthropology and sociology. This is to acknowledge that technological innovations and, in our case, the mobile devices, are only the most visible aspect of a vast area of social and cultural changes of our own time. Some researchers have already discussed netnography and digital ethnography (Caliandro, 2012), while others are currently studying the identification processes that remodulate in the rich area of relations allowed by the network, and still others are involved in hypotheses that have more of a Promethean feel. All this, in any case, makes you think that mobility can take on a whole new face, and yet still be universal.

The great potential of mobile learning devices hooks up these new contexts that are, above all, cultural and social, but also organisational and relational, forcing us to reconsider fundamental themes of pedagogical discourse. Among these themes, the first must be the construction of the student's identity and, connected to this, the issue of personalised education.

b) The second issue arises from the need to give due place to what appears to be the most striking aspect: the ability to read, write and follow a lesson in distance learning, not only out of the classroom, but also out of a well-defined domestic area. These new technological resources fundamentally alter the boundaries of the traditional classroom and force them to be equivalent with the space in which distance learning takes place. This is not only an expansion of the educational setting, but instead a substantial alteration, combined with a substantial modification of the entire experience of educational relationships (both vertical and horizontal) and the entire range of communication channels, which are then exposed to distorting phenomena (both positive and negative) of unpredictable intensity, quality and durability.

To give only one example, albeit minor in relation to matters far more significant, we must revise the timing of attention and the method to provide motivational support to the learners who are potentially exposed to factors that may distract them.

c) The third question arises from the acknowledgment of the significant impact that mobile communications tools have on learning, so much so that educational directives had to immediately gear up to accept the challenge in terms of

\footnotetext{
${ }^{1}$ Jumptap is a small company based in Boston, recently taken over by Millennial Media. It is a company that provides technologies, tools and services to application developers and publishers interested in working in function and mobile devices.
} 


\section{Educational research between on devices and mobile learning Martiniello, Paparella}

revising management parameters of the educational setting, especially in reference to the specific use that, in some countries, including Italy, sees distance learning being mainly used by adults engaged in higher education or vocational training courses.

If, in fact, the more widespread use of mobile devices covers essentially the same age groups that are most affected by the activities of distance learning, we can then understand why there exists this attention and critical reflection to better understand what the impact of mobile devices for communication means.

These three questions help depict the complex problematic web that explains the critical nature of the impact, due to and implemented by not only the adjustments required by the novelty of these tools, but also by the rules created to unnecessarily hinder the presence of mobile technology in education. We passed, in a short period of time, from the ban on bringing phones into the classroom to the intelligent use of the tablet to download and read documents or, even more significantly, to connect to Interactive Whiteboards and contribute to the construction of a lesson (Martiniello, 2014; Moricca, 2016; Rivoltella, 2014).

And so we have now come to the main question, the one which interests us the most, the one we can think of as a revolutionary turning point. We ask ourselves: Does the opportunity to learn anywhere and at any time only promise to extend and amplify the spaces and usage times, or does it instead indicate a breakdown and a reconstruction of the learning environment, with a contiguous deconstruction of classical pedagogical antinomies?

The promises of mobile learning to learn anytime, anywhere and always on the go can be traced back to classical themes (e.g. relationship between formal and informal learning, school and extracurricular school), which when considered under the lens of mobile learning, are likely to be exasperated, exterminated [...] If we assume mobile learning in its "strong" (learn anywhere, at any time and always in motion) and compare it with some pairs of "classic" concepts of education (formal/informal, education and learning, etc.), antinomies can be created and it can be difficult to find a peaceful settlement to these opposites. It will be necessary then to find a way out of the risk of incompatibility.

Let us consider, for instance, the by-now familiar distinction between formal, informal and non-formal education. Compared with formal learning, we have always considered the two conditions of informal and non-formal education as independent or at least parallel, but essentially distinct and fundamentally different (Bardulla, Paparella, 2005; Ravicchio, Trentin et Repetto, 2015). In the moment in which teaching is done through mobility, and therefore with the effects of interference in contexts completely different from those that are somewhat predictable by the designer of distance learning, can we still think of a "distinction" between formal and informal or, at least, should we not assume a sort of context cross-breeding?

The question does not arise from quantitative considerations (e.g. how much information is learned from formal sources and how much from other sources), but it instead arises from qualitative evaluations. Will the young student who follows his/her online lesson while taking the underground from one corner of the city, and then continues to do his/her exercises (still online) under the oak tree in the public park find always and only distractors? And if this were to be true, is it not right to ask the meaning of this new situation?

In our opinion, here exists a paradigm: the learning context not only escapes the teaching team's realm of predictability, but somehow eludes even the predictability of the learner, and indeed, it is the very nature of the context that takes completely different characteristics and connotations.

In this respect, it would aid to apply the idea of "context" to what Lewin said about his idea of field, but here the investigation is in progress (Lewin, 1936).

The problem is complex. Before solving it, indeed, before planning the paths that can lead to the solution, it is necessary to get help from Bacone and eliminate some idola fori and some idola tribus.

Maybe we have to deal with a certain fallacy of language (idola fori). The same distinction between formal, informal and non-formal education should be reconsidered, as should be the definition of lifelong learning. Not because one thinks of a different meaning between these terms, but to deal with, explicitly, that sort of "philosophical" convention that is present in the speeches that make use of these words. As Maritain asserted, "we have to separate in order to link" (Maritain 1932). We are not saying that formal, informal and non-formal are not contexts, fields and distinct moments, but we are stating and are pointing out that they are interacting modalities. We have to think of a deep integration between these three modalities that must be thought of as distinct in order to understand them and manage them, but that act along unitary integrated lines (Leone, 2013).

As for the idola tribus, it is important to at least reconsider the pseudo certainties related to the primary source of learning, the asymmetries of the educational setting, the unjustified preclusions against sources of learning and, above all others, the unjustified gap between knowledge and skills that sometimes conditions (secretly) some of our educational settings.

We are now left to seek out and expose some idols specus (e.g.: "we have always done it like this"), and some idola theatri (mainly as a result of some mechanical behaviorism) on which we will not dwell on in this occasion.

If we look carefully and at an effective critical distance, it should not be difficult to see that teaching though a smartphone has the same constraints that are usually faced by those who design distance learning programmes. It would be enough to think about the times and rhythms of the lesson as well as the distribution of teaching materials and their 


\section{Educational research between on devices and mobile learning Martiniello, Paparella}

hypermedia, as well as cross-media significance. Clearly, the target taken into account by tutorial managers is completely different from that of the consumer in mobility.

Then if we specify the condition of the student, we often find that the didactic material, driven by the understandable demands of generalisation of scientific propositions, has become simplified and outlined to the point of considering the student as an isolated person: who is surely vulnerable to interferences, stresses and stimuli of culture, to history and the social group, but who is in fact isolated and lonely at the time of learning. The something is, in fact, a simplification and therefore also, to a certain extent, a falsification.

Now, online learning through a handheld device uncovers this schematic outline and forces you to take note of the coefficient of artificiality that the scheme comes along with. Not only that, but it also forces you to seek out the positive aspects beyond the possible interferences, which can distort the message.

We are on the verge of justifying a major revision of some paradigms that relate to the nature of the context, the role of the teacher and the position (in the sociological sense) of the student, which also affect the nature of the message and, more generally, the "entire educational setting".

It means working in this direction.

Meanwhile, here, after having raised the issue, we should deal with some of the corollaries, starting with those most obvious.

Many people today talk of the recognition of credits for the benefit of those who may have, under certain conditions, non-formal learning and informal learning, alongside the more famous formal learning. Is this discussion still useful or does it instead need some significant clarification?

If we really have to think of a sort of cross-breeding of the three ways of learning, and if we have to recognise that in the context of lifelong learning, the advantages that can be recorded on only one of the three sides (formal, informal and non-formal) are derived from all three sides, together, and if in the dynamics of learning, due to the widening of context, personal enrichment is realised, once again, on all three modes, if we take note of what we have discussed so far, it is clear that we need to revise many of the "certainties" with which we provided motivation and support to the prevailing practice of recognition of academic credits.

Surely, there is still a need to understand the actual profile of the student and to recognise what he/she claims as his/her actual abilities (Paparella \& Iervolino, 2013). The operation, however, should not be conducted by examining the source, but by looking at the actual configuration that learning takes in his/her personal universe. We need to think about learning and abilities as the pieces of a mosaic that gives us a dynamic profile of the person. What we should do then, regarding orientation initiatives or educational guidance, is to look for any "stretch marks" of that profile and associate educational debts, i.e. the tasks of learning, integrative experiences and moments of growth, through which it is possible to complete the profile ${ }^{2}$.

Another corollary that should be discussed, in the economy of this work, is the thorough revision of the concept of the learning environment, on which much has been written and on which much is still to be discussed in order to fully understand the paradigmatic effects of impact in association with mobile devices. We will have to reread what Wittgenstein wrote about the word "context", we will have to consider the size of the references due to mobility, but mostly we will have to consider (this is the new paradigm) the inner dimension of the context. However, we will revisit this subject on another occasion.

\section{References}

Bardulla, E. Paparella, N. (2005) (a cura di). La ricerca didattica nei contesti formali, non formali, informali. Roma: Monolite.

De Simone. G. C. (2012)Mobile Learning. Tra ubiquità e mobilità, Report for the VI Seminario Sird. Retrieved from http://www.sird.it.

Hayes, P. Pathak, P. et Al. (2005). Cultural-Context of Mobile Learning using Activity Theory, Proc. Of the 6th Annual Irish Educational Technology Users' Conference, Irish Learning \& Teaching Association, Sligo (Ireland), 2006.

Leone, S. (2013 October). Synergic Integration of Formal and Informal E-Learning Environments for Adult Lifelong Learners. USA: IGI Global.

Lewin, K., (1936). Principi di psicologia topologica. tr. it.,(1961). Firenze: OS.

Lewin, K., (1951). Teoria e sperimentazione in psicologia sociale. tr. it., (1972) Bologna: Il Mulino.

Maritain, J. (1932). Distinguere per unire. I gradi del sapere. tr. it., Brescia: Morcelliana.

Martiniello, L. (2014). La didattica mediale nel postmoderno. Napoli: Giapeto.

Moricca, C. (2016). L'innovazione tecnologica nella scuola italiana. Per un'analisi critica e storica, in Form@re, Vol. 16 Issue 1, pp. 177-187.

Paparella, N. \& Iervolino, D. (2013). Professioni Autoregolamentate. Formazione, tutela, deontologia. Napoli: Guida.

\footnotetext{
${ }^{2}$ The task may appear difficult but is not impossible. A team led by Paparella is working on the corollary of the work shown by the aforementioned volume.
} 
Pieri, M. Diamantini, D. (2009). Il mobile learning. Milano: Guerini e Associati.

Ravicchio. F., Trentin. G., Repetto. M., (2015) Formazione in rete, teleworking e inclusione lavorativa. Milano: Angeli.

Rivoltella, P.C., (a cura di) (2014). Smart Future. Didattica, media digitali e inclusione. Milano: Angeli.

Rossi, P. G. (2009) Tecnologie e costruzione di mondi. Roma: Armando.

Sharples, M. (2006). Big Issues in Mobile Learning. Report of a workshop by the Kaleidoscope Network of Excellence, Mobile Learning Initiative. University of Nottingham: LSRI.

Traxler, J. (2009) Learning in a Mobile Age. International Journal of Mobile and Blended learning, vol. 1, n. 1, pp. 112.

Weishaupt, F. from http://www.jumptap.com/offers/cross-screen-study.

http://www.zenithoptimediagroup.it/notizie-e-novita/il-consumo-di-internet-da-mobile-crescera-del-28-per-cento-nel2016 . 